\title{
Vozes marginais em Fogo morto, de José Lins do Rego
}

Aurora Gedra Ruiz Alvarez
Universidade Presbiteriana Mackenzie
LÍLIAN LOPONDO

Universidade de São Paulo

Universidade Presbiteriana Macken rie

RESUMO: A LINGUAGEM CONSTITUI-SE DA IDEOLOGIA DO GRUPO SOCIAL QUE A ATUALIZA. FOGO MORTO, ROMANCE DE JOSÉ LINS DO REGO, NARRA A SAGA DA SOLlDÃO E DA EXCLUSÃO SOCIAL VIVIDA POR JOSÉ AMARO. O VETOR QUE IMPULSIONA AS AÇÕES DA PERSONAGEM ESTÁ LIGADO ÀS RAÍZES CULTURAIS DE UMA PEQUENA ClDADE NORDESTINA DO FINAL DO CICLO DA CANA-DE-AÇÚCAR, ONDE AS NORMAS SOCIAIS SE TORNAM O DIVISOR DE ÁGUAS PARA A INTEGRAÇÃO AO MEIO. ESTE SERÁ O EIXO DAS TENSÕES VIVIDAS PELO PROTAGONISTA.

O OBJETIVO DO NOSSO ESTUDO É O DE ANALISAR AS FORMAÇÕES IDEOLÓGICAS QUE CONSTROEM AS RELAÇÕES SOCIAIS NO MUNDO DE JOSÉ AMARO E O DE EXAMINAR AS SOLUCCÕES LITERÁRIAS QUE JOSÉ LINS DO REGO ELEGE PARA DAR CORPO A ESSE ETHOS NO PROCESSO CRIADOR.

RESUMEN: EL LENGUAJE SE CONSTITUYE DE LA IDEOLOGÍA DEL GRUPO SOCIAL QUE LA ACTUALIZA. EN FUEGO MUERTO, DE JOSÉ LINS DO REGO, EL VETOR QUE PONE EN MARCHA LAS ACCIONES DEL PERSONAJE ESTÁ RELACIONADO A LAS RAÍCES CULTURALES DEL CICLO DE LA CAÑA DE AZÚCAR, DONDE LAS NORMAS SOCIALES DEL PATRIARCADO SE CONVIERTEN EN DIVISOR DE AGUAS PARA LA INTEGRACIÓN AL MEDIO.

EL OBJETIVO DE NUESTRO ESTUDIO ES EL DE ANALIZAR LAS FORMACIONES IDEOLÓGICAS QUE CONSTRUYEN LAS RELACIONES SOCIALES EN EL MUNDO DE JOSÉ AMARO Y EL DE EXAMINAR LAS SOLUCIONES LITERARIAS ELEGIDAS POR JOSÉ LINS DO REGO PARA DARLE CUERPO A ESE ETHOS EN EL PROCESO CREADOR.

PALAVRAS-CHAVE: FOGO MORTO, FICÇÃO, IDEOLOGIA, JOSÉ LINS, VOZES MARGINAIS. PALABRAS-CLAVE: FUEGO MUERTO, FICČ̃̃O, IDEOLOGIA, JOSÉ LINS, VOCES MARGINAIS. 
ogo morto recria a vida e a mentalidade do mundo nordestino na fase da canade-açúcar, privilegiando uma linguagem viva, espontânea, que dá larga à memória. O discurso do narrador não se limita a contar uma velha história do ciclo da cana. À técnica memorialista sobressai-se a criação: o romance não se inscreve, portanto, nas funções proselitistas da arte engajada. Embora as estruturas sociais do engenho de cana permeiem a tessitura narrativa, é evidente que José Lins do Rego transpõe essa realidade social através das convenções lingüísticas que constroem os dramas das personagens de maneira peculiar, fazendo com que elas tenham vida própria no mundo da ficção.

A narrativa divide-se em três partes, centralizando em cada uma delas o drama de um protagonista. Contudo estas três personagens entrecruzam-se dentro do espaço e tempo narrativos, construindo conjuntamente a composição de um triângulo. Se cada linha dessa figura geométrica ocupa um espaço próprio, será, contudo, apenas com os encontros dos extremos que se comporá a figura.

A trama narrativa encarrega-se de engendrar três personagens vivas, tensas e com existência própria, confrontando entre si modos distintos de ver o mundo: o mestre José Amaro, o Coronel Lula de Holanda e o Capitão Vitorino. Alegoricamente cada uma destas personagens representa um estrato da sociedade do ciclo da cana. Assim como na estrutura social da época essas classes sociais estavam uma em função ou em dependência da outra, é importante notar que, também na narrativa, elas se aproximam na medida em que apresentam traços culturais comuns como: orgulho de sua posição social, ressentimentos profundos pela perda do respeito e da consideração do seu grupo e pelo isolamento e/ou marginalização. Por outro lado, são três existências diferentes que levam consigo dramas diversos. Entretanto nos ateremos apenas à análise da personagem José Amaro.

A proposta de nosso trabalho é a de analisar as formações ideológicas que constroem as relações sociais no mundo de José Amaro e a de examinar as soluções literárias que José Lins do Rego elege para dar corpo a esse ethos no processo criador.

$\operatorname{Em} A$ ideologia alemã, Marx e Engels afirmam que a consciência "só aparece com a carência, com a necessidade dos intercâmbios com os outros homens".

\footnotetext{
${ }^{1}$ MARX, Karl; ENGELS, Friedrich. A ideologia alemã. Trad. Luis Cláudio de Castro e Costa. São Paulo: Martins Fontes, 2002. p.24.
} 
Este pensamento desenvolve-se ainda mais com os estudos de Bakhtin que considera a consciência como fato social, ou seja, um indivíduo pensa e age, via de regra, levando em conta a conduta estabelecida pelos demais componentes de sua coletividade.

Tomando como base essas considerações, torna-se imprescindível refletir sobre as formações ideológicas que enformam as ações da personagem e as suas condições de inserção na sociedade. Como falamos anteriormente, a obra tem suas raízes no contexto sócio-econômico cultural do final do século XIX da região nordeste do Brasil e será nesse substrato econômico e ético que o drama existencial de José Amaro medra vertiginosamente.

A personagem é introduzida em plena ação, servindo-se de um diálogo estabelecido entre ele e o pintor Laurentino. A seguir, o narrador, assumindo a visão "por trás", segundo a terminologia de Jean Pouillon (1974), revela os seus poderes demiúrgicos e inicia a diegese, desnudando aos poucos a intricada teia das relações entre José Amaro e o meio. No processo de construção da narrativa, ganham relevo os verbos no pretérito imperfeito. $\mathrm{O}$ aspecto verbal do tempo escolhido sugere-nos uma categoria durativa da ação, um expediente de atualização dos acontecimentos. É a forma privilegiada pelo narrador para convocar o leitor a compartilhar do momento da elocução. As manifestações dos sentimentos, das idéias da personagem presentificam a narrativa e escandem um ritmo acelerado, tenso no discurso:

Quando voltou para a cozinha o mestre retornou à vida que o alimentava, aos homens que precisavam dos seus serviços. Agora não estava mais consertando os arreios de um velho doido, não estava fazendo sela para um camumbembe qualquer. Trabalhava para o grupo de Antonio Silvino. Cortava solas para cabras que já sabiam morrer no rifle, para gente que tinha sangue de macho. Não era um pobre seleiro de beira de estrada, era mais que um oficial de bagaceira de engenho. O Capitão Antonio Silvino sabia de seu nome. Sem dúvida que Alípio lhe diria: "Capitão, o Mestre José Amaro trabalha para nós. É homem de confiança”. Que fossem para o inferno os grandes da terra. ${ }^{2}$

${ }^{2}$ REGO, José Lins do. Fogo morto. 6. ed., Rio de Janeiro: José Olympio, 1965, p. 82. 
Como podemos observar, o fragmento capta uma ação pontual do passado ("voltou para a cozinha") e, em seguida, libera o fluxo do pensamento do protagonista mediante o uso do solilóquio e de discurso indireto livre. Estes recursos revelam o conflito da personagem com o grupo. Assim, o seu discurso propicia a sua absoluta transparência e projeta tanto as expectativas que o meio tem em relação a ela quanto as suas reações diante das coerções sociais.

$\mathrm{O}$ arcabouço cultural da sociedade plasmada na narrativa apresenta características medievais. O respeito configura-se como um dos valores que transcende o plano do indivíduo e espelha as atitudes morais de uma sociedade de castas: o senhor de engenho, os bacharéis, o artesão e o escravo. Estão impregnados nessa comunidade: um respeito fetichista como o "orgulho de branco", o preconceito, a discriminação racial, a servidão feminina, o machismo e a superstição.

A personagem José Amaro configura-se no tempo e no espaço e funciona, sobretudo, como receptor e difusor de informações. Sua casa é o núcleo onde todas as personagens travam diálogo com o mestre e de onde desaparecem, dando ocasião, então, aos solilóquios do protagonista. É por meio das outras personagens que o seleiro toma conhecimento dos boatos e dos acontecimentos daquela região. A partir dessas intrusões no seu pequeno mundo, José Amaro vai aos poucos se revoltando contra a sociedade aristocráticorural e contra os desmandos da polícia. Torna-se uma personagem ressentida. "É o que digo a todo mundo. Não agüento grito. Mestre José Amaro é pobre, é atrasado, é um lambe sola, mas grito não leva."”

Notemos que essa conduta de não submissão ao domínio de alguém ou de um grupo bem como a não aceitação da perda do respeito estão ligados à ordem social. O mestre é uma personagem que dentro do período áureo da cana-de-açúcar estava ligada ao senhor de engenho. Com a decadência do ciclo da cana, assiste à derrocada do Coronel Lula de Holanda. Dessa feita, José Amaro deixa de lhe fazer peças dignas de um artífice para executar pequenos consertos para uma clientela pobre. Ao mesmo tempo, ele não se submete às ordens do Coronel José Paulino, representante da nova oligar-

\footnotetext{
${ }^{3}$ REGO, José Lins do. Fogo morto. 6. ed., Rio de Janeiro: José Olympio, 1965, p. 9.
} 
quia - aquele que soube se adequar aos avanços da tecnologia. Assim, o seu conflito transita da decadência do antigo engenho e da sua dignidade de artesão para o desrespeito dos novos senhores e a perda do seu estatuto de mestre da arte de trabalhar o couro. Por isso apresenta o "orgulho de branco" ferido, que se acerba principalmente quando José Paulino desrespeita-o, tratando-o como escravo.

É importante lembrar que nessa sociedade que está emergindo do processo de abolição da escravatura, o negro ainda recebe o mesmo tratamento discriminador nas relações sociais da fase anterior. Ou ele é visto como uma figura matreira, amiga de intrigas e difamações como Floripes ou, via de regra, como um excluído até das relações de trabalho, como Passarinho. Em grande parte da narrativa, este último aparece como um alcoólatra, mal cuidado, sempre comparado aos bichos. Só no final de sua vida, José Amaro percebe a dimensão humana de José Passarinho expressa, principalmente, pela afabilidade e pelo carinho que este tem por si:

Passarinho, dentro de casa, lhe parecia agora outro homem. Há muito que o negro não bebia. Era ali em sua casa, quem lhe cozinhava o feijão, quem lhe fazia as coisas. Era um bom negro. Via-o sujo, de pés cambados, de olhar quase morto, e mesmo assim o julgava mais feliz do que ele. ${ }^{4}$

Neste contexto de raízes ainda escravocratas, o referencial de rebaixamento social é o negro, como transparece na fala do protagonista ao contar a invasão do grupo de Antônio Silvino no engenho Santa Rosa: “(...) A filha do Coronel José Paulino servira a mesa para os cangaceiros, como se fosse uma negra, uma criada."

Por isso, José Amaro sente um aviltamento da sua condição ao ser tratado aos gritos como "cabra da bagaceira". Entretanto, com o desenvolvimento da personagem e com o crescimento em tensão da mesma, vemos o desligamento do mundo que o cerca, do mundo em função dos senhores de engenho que o degradam socialmente. Em contrapartida, José Amaro extravasa sua revolta,

${ }^{4}$ REGO, José Lins do. Fogo morto. 6. ed., Rio de Janeiro: José Olympio, 1965, p. 207-208.

${ }^{5}$ Id. Ibid. p. 83. 
expressando-se numa linguagem violenta e agressiva e vê, então, no seu trabalho, refúgio para essa ira incontida. Além disso, amarguram-no os fatos de não ter atingido o prestígio profissional de seu pai e o de não ter um filho.

Em uma sociedade primitiva como esta enfocada pelo romance, a mulher desempenha o papel necessário à reprodução. Desta função social espera-se que ela dê à luz um varão para ser o herdeiro dos bens e/ou da profissão paterna. Se, ao contrário das expectativas, nascer uma menina, cria-se a expectativa de que esta seja bem adestrada nas prendas domésticas para casarse e dar continuidade à família. Em vários momentos na narrativa, encontramos o preconceito social contra a mulher solteira com idade superior a trinta anos, considerada "que está no caritó", ou seja, fadada a não mais se casar. A coletividade age rudemente contra estas jovens, recorrendo-se a um antigo costume de, na quaresma, "serrar moça velha", "serrar o caixão". Simbolicamente, este ritual evidencia a punição do grupo que desconsidera a importância dessa mulher para a comunidade, ou seja, como ela deixou de cumprir a sua função social, pode ser "serrada", colocada no caixão, morta. O resultado destas sanções sociais é o insulamento e a auto-anulação da jovem.

Alexandre Pinheiro Torres, em "Depoimentos em ficção sobre a situação da mulher" (1967), registra que o comportamento que reforça o conceito da inferioridade feminina no contexto social remonta aos tempos antigos. $\mathrm{O}$ cristianismo sedimentou ainda mais esta idéia de servidão, de obediência e de carência de proteção, devido à fragilidade da mulher no contexto social.

No citado ensaio, Pinheiro Torres defende a idéia de que a inferioridade feminina, alimentada pela sociedade ao longo dos séculos, é fruto do "mito da vassalidade", isto é, da servidão da mulher, restrita ao seu papel de reprodutora e de mantenedora da ordem estabelecida pelo pater familias.

De acordo com Simone Beauvoir em O Segundo Sexo $0^{6}$ até mesmo o "mito sublimador" burguês de endeusar a mulher, de santificá-la, dá continuidade ao "mito de vassalidade", como faz, no início, o Coronel Lula de Holanda na sua relação com D. Amélia. Assim, tanto na situação em que o homem trata a mulher como objeto, reificando-a ou quando tenta sublimá-la, nega-lhe a

\footnotetext{
${ }^{6}$ BEAUVOIR, Simone. O Segundo Sexo. Apud: TORRES, Alexandre Pinheiro. "Depoimento em ficção sobre a situação da mulher”. Romance: o mundo em equação. Lisboa: Portugália, 1967, p. 104.
} 
humanidade e, por extensão, passa a considerar a si, homem, como o tipo humano absoluto.

Interessantemente, esta óptica burguesa desvela-se na narrativa nas falas de José Amaro através do leitmotiv. Na conceituação de W. Kayser, ${ }^{7}$ este recurso retoma certos motivos que se repetem na obra e, que, por sua vez, constituem traços significativos da personalidade da personagem:

Lá para dentro ouvia-se um gemer de voz, um cantar de ladainha. O mestre Zé Amaro parou um instante, como se prestasse atenção à cantiga.

- Pára com isto menina! Pára com isto. Não quero ouvir latomia de igreja na minha casa.

- Deixa a menina, Zeca. Vai bater sola.

- É o que sabe dizer esta vaca velha.

E levantando a voz num grito:

- Pára isto. Não quero ouvir latomia de igreja. Na minha casa manda o galo (grifos nossos). ${ }^{8}$

Ainda:

(...) Ouvia o gemer da filha (...). A filha continuava chorando como se fosse uma menina. O que era que tinha aquela moça de trinta anos? Bem que podia ter tido um filho, um rapaz como aquele Alípio, que fosse homem macho, de sangue quente, de força no braço. Um filho do mestre José Amaro que não lhe desse o desgosto daquela filha (...). Voltava outra vez à sua mágoa latente: $\mathrm{O}$ filho que lhe não viera, a filha que era uma manteiga derretida. Sinhá, sua mulher, era a culpada de tudo (grifos nossos). ${ }^{9}$

Os fragmentos ilustram bem o que explanamos acima. O leitmotiv "na minha casa manda o galo" expressa tanto a autoridade de chefe de família que não pode ser contestada quanto a reificação da mulher que se torna objeto

\footnotetext{
${ }^{7}$ KAYSER, Wolfgang. Análise e interpretação da obra literária. Trad. Paulo Quintela. 4. ed., Coimbra: Armênio Amado, 1967. vol.1. p. 100.

${ }^{8}$ REGO, José Lins do. Fogo morto. 6. ed., Rio de Janeiro: José Olympio, 1965, p. 7.

${ }^{9}$ Id. ibid. p. 8-9.
} 
disposto dentro desse contexto de acordo com os desejos do homem. Se as ações imperativas e a visão possessiva em relação aos objetos e seres ("minha casa", "sua mulher") reforçam a centralização do eixo familiar nas mãos do patriarca, mantendo a mulher na posição de submissão, a expressão chula "vaca velha", precedida pelo dêitico "esta", por funcionar como demonstrativo, distancia ainda mais o avaliador do ser depreciado, marginalizando-o.

Também o leitmotiv - "Sinhá, sua mulher, era a culpada de tudo" - apresenta a função predicativa ("a culpada de tudo") destacada pelo dêitico que aponta a esposa como a única responsável pelos fracassos do protagonista. $\mathrm{Na}$ sociedade tradicional do século XIX, o homem comparece como provedor da família, enquanto a mulher, como já vimos, responde pela preservação da ordem domiciliar. Dentro das atribuições desenvolvidas pela figura feminina insere-se a criação dos filhos e, até mesmo, a culpa de gerar filhas em vez de varões.

Embora José Amaro enderece a outrem a responsabilidade de suas frustrações, estas recorrências vão minando-lhe as forças, destruindo as suas defesas, na mesma proporção em que vai recrudescendo a angústia que o deixa inapto a comunicar-se com sua família e com o meio. Esse distanciamento mergulha-o na solidão e na inação.

Assim, podemos dizer que o dominante caracterológico do mestre José Amaro é a inércia. Esta atitude tem duas implicações: reflete a impotência e uma transferência de sua ação e de seus desejos a uma terceira pessoa. Em segundo lugar, implica um estreitamento de vínculo com o passado que atua simultaneamente como esquema de valor e como elemento catalisador de sua destruição.Toda sua vida profissional se pauta pelo exemplo de seu pai. No entanto verifica-se que entre o pai e ele houve uma enorme dissensão, que atua fortemente no seu desmoronamento humano, pois se sente desvalorizado e ameaçado a perder a posição de branco, uma vez que seu trabalho é feito para "camumbembes", ou seja, para pessoas pobres. Neste caso, o passado é o modelo que não pode ser atingido:" [O seu pai] Era mestre de verdade. Só queria que o senhor visse como aquele homem trabalhava na sola. Uma peça dele foi dada pelo Barão de Goiânia ao Imperador". ${ }^{10}$

\footnotetext{
${ }^{10}$ REGO, José Lins do. Fogo morto. 6. ed., Rio de Janeiro: José Olympio, 1965, p. 6.
} 
De acordo com Sérgio Buarque de Holanda, na sociedade pré-capitalista, "o gosto artístico, a destreza, o talento pessoal, que são virtudes cardeais na economia do artesanato, passam assim ao plano secundário, ${ }^{11}$ ou seja, o trabalho manual é considerado pouco dignificante para o contexto social da segunda metade do século XIX. Trabalhar para os grandes senhores de engenho ou até para a nobreza, como seu pai, alçá-lo-ia a uma posição privilegiada socialmente e aproximá-lo-ia do estamento do branco. O contrário, ser "um pobre seleiro de beira de estrada", executando serviços ordinários para viajantes comuns, degrada-o ao estatuto do trabalhador braçal, disposto especialmente para os negros e mestiços na sociedade do ciclo da cana.

Em meio a tantas mágoas, José Amaro lança-se, para uma ação que o liberta das humilhações e ressentimentos. Por não ter um filho que o defenda, o cangaceiro Antônio Silvino assume as feições do vingador coletivo de todas as frustrações e, por outro lado, o seu pacto com Antônio Silvino representa uma forma de sublimação profissional, pois trabalhando para ele, sente-se "mais que um oficial de bagaceira de engenho." 12

A ação do cangaceiro aparece fragmentariamente duas vezes enquanto que a ação da polícia é descrita minuciosamente. Antônio Silvino e o seu grupo agride somente a classe dominante e, em geral, age de acordo com os valores do povo, ou seja, respeita mulheres, donzelas, velhos e crianças, ao contrário dos desmandos do Tenente Maurício e de sua tropa.

A heroicização de Antônio Silvino decorre da incapacidade da personagem descobrir uma saída tanto para aquela situação de desestruturação social, quanto para, indiretamente, resgatar os seus valores humanos. O cangaceiro é o filho que ele não teve e que poderia vingá-lo das desconsiderações sofridas: “(...) O nome de Antônio Silvino exercia sobre ele um poder mágico. Era o seu vingador, a sua força indomável, acima de todos, fazendo medo aos grandes." 13

O mestre José Amaro está incrustado em uma sociedade de características estamentais. Em Raízes do Brasil, comenta Sérgio Buarque de Holanda:

\footnotetext{
${ }^{11}$ HOLANDA, Sérgio Buarque de. Raízes do Brasil. 6.ed., Rio de Janeiro: José Olympio, 1971. p. 52.

${ }^{12}$ REGO, José Lins do. Fogo morto. 6. ed., Rio de Janeiro: José Olympio, 1965, p. 82.

${ }^{13}$ Id Ibid. p. 57-58.
} 
(...) nos domínios rurais, a autoridade do proprietário não sofria réplica. Tudo se fazia consoante sua vontade caprichosa e despótica. O engenho constituía um organismo completo e que, tanto quanto possível, se bastava a si mesmo. ${ }^{14}$

A família patriarcal do ciclo da cana além dos seus membros consangüíneos congrega ainda os escravos e os agregados. Desta forma, ela fornece o grande modelo pelo qual se hão de "regular a boa harmonia do corpo social." 15 Esta sociedade tem como escopo a atitude paternalista para quem cumpre as normas e a despótica para quem as desobedece. $\mathrm{Na}$ obra em estudo, a personagem vê a desagregação deste paradigma, na medida em que os coronéis se curvam diante da ação do cangaço e da polícia. Sem força política, muitos empobrecem como o Coronel Lula de Holanda, perdendo o seu estatuto de senhor de engenho.

Diante dessa desestruturação social, o protagonista encontra-se desajustado. O núcleo mais reduzido da sociedade, isto é, sua família também se desarticula. A permanência de alguns elementos do passado nessa sociedade em rápida transformação surge como aparições fantasmagóricas. O tilintar das campainhas do antigo cabriolé do Coronel Lula de Holanda ecoando nos estradões e o som do velho piano de D. Amélia, esposa do Coronel, fomentam os delírios de um fausto que não mais existe. Por isso, José Amaro retorna ao passado através dos seus leitmotive, com o objetivo de recuperar o padrão social constituído pela autoridade de pater familias, pelo machismo, pela valorização profissional, pelo "orgulho de branco". A recorrência aos antigos valores reveste-se de ressentimento e de agressividade no trato com a coletividade. Instaura-se, assim, a ruptura com o meio e inicia-se o insulamento da personagem. Torna-se, então, ainda mais inviável a possibilidade de integração no novo modelo. Desenvolve-se o processo de marginalização da personagem pelo grupo que começa a encontrar no comportamento do mestre, assim como nas suas deformações físicas, provocadas pela doença cardíaca e pelo constante contato com o couro, a amarelidão e o inchaço do lobisomem. Dessas observações surge a interpretação das "evidências", como sendo as do comportamento de vampirismo. A imaginação popular prodiga-

${ }^{14}$ HOLANDA, Sérgio Buarque de. Raíres do Brasil. 6.ed., Rio de Janeiro: José Olympio, 1971. p. 48.
${ }^{15}$ Id. Ibid. p. 53. 
liza-se em encontrar traços de licantropia, que vão desencadear o processo de satanização da personagem que percorrerá uma trajetória rápida, graças ao arcabouço cultural daquela comunidade, extremamente afeta aos boatos e superstições. Todos passam a considerá-lo um lobisomem, ou seja, aquele que tem contato com as regiões ínferas.

As superstições e o misticismo religioso representam a estrutura dorsal da cultura da sociedade caracterizada nessa narrativa. Por isso ela vê os endemoninhados como seres malditos. Ademais, o mundo das trevas configura-se para esse meio como maldição que aqueles que fizeram o pacto com Satã não conseguem vencer. Inserida nesse contexto social cristalizado pela tradição, a personagem é condenada ao ostracismo.

Em síntese, José Amaro vive preso ao seu motif - a desarticulação com o contexto social. Com o recrudescimento desse conflito externo, a tensão interna manifesta-se em um ritmo acelerado, como em um movimento de "fuga", com acordes gritantes do finale. O crescente isolamento - sentimento de abandono de sua família -, a incapacidade de comunicação e de adaptação ao meio, enfim, todos esses fatores criam em José Amaro um processo de estranhamento, que se acentua ainda mais com a opressão social, que transborda com a prisão. O refúgio das coerções sociais que o protagonista encontra no pacto com Antônio Silvino torna-se vulnerável. A opressão do grupo social mina-lhe as resistências físicas e psicológicas. Na sua alma germina o inferno interior, o conflito íntimo que o leva à morte.

Como vemos o legado ideológico de um grupo não implica apenas a sua incorporação pelo indivíduo, mas também e, sobretudo, a sua veiculação por esse mesmo sujeito que o experimenta. A interação entre a ideologia e o ser humano é recíproca, não excludente, pois, ao mesmo tempo em que as regras sociais moldam o comportamento de um indivíduo, elas são representadas ativamente por ele, que as atualiza, atribuindo-lhes, por conseguinte, estatuto de signo incontestável. Portanto, no momento em que José Amaro cria o seu mundo, recusando-se a partilhar da norma que preconiza um convívio de relações estreitas, próprias do seu universo, ele rompe com o processo de legitimação da tradição. A conseqüência dessa desincompatibilização é o seu banimento do grupo social.

O suicídio é o resultado de seu orgulho ferido e do ressentimento daquele mundo. A personagem, desta forma, nega-se a pactuar com ele. Este ato é o 
máximo de abertura da personagem que responde frontalmente ao grupo, excluindo-se dele.

\section{Referências bibliográficas:}

HOLANDA, Sérgio Buarque de. Raízes do Brasil. 6.ed., Rio de Janeiro: José Olympio, 1971.

KAYSER, Wolfgang. Análise e interpretação da obra literária. Trad. Paulo Quintela. 4. ed., Coimbra: Armênio Amado, 1967. vol.1.

MARX, Karl; ENGELS, Friedrich. A ideologia alemã. Trad. Luis Cláudio de Castro e Costa. São Paulo: Martins Fontes, 2002.

POUILLON, Jean. O tempo no romance. Trad. Heloysa de Lima Dantas. São Paulo: Cultrix / EDUSP, 1974.

REGO, José Lins do. Fogo morto. 6. ed., Rio de Janeiro: José Olympio, 1965.

TORRES, Alexandre Pinheiro. "Depoimento em ficção sobre a situação da mulher”. Romance: o mundo em equação. Lisboa: Portugália, 1967. 